\title{
Autosomal dominant spastic paraplegia type 4
}

INSERM

\section{Source}

INSERM. (1999). Orphanet: an online rare disease and orphan drug data base. Autosomal dominant spastic paraplegia type 4. ORPHA:100985

Autosomal dominant spastic paraplegia type 4 (SPG4) is a form of hereditary spastic paraplegia with high intrafamilial clinical variability, characterized in most cases as a pure phenotype with an adult onset (mainly the 3rd to 5th decade of life, but that can present at any age) of progressive gait impairment due to bilateral lower-limb spasticity and weakness as well as very mild proximal weakness and urinary urg ency. In some cases, a complex phenotype is also reported with additional manifestations including cognitive impairment, cerebellar ataxia, epilepsy and neuropathy. A faster disease progression is noted in patients with a later age of onset. 